\title{
Design Principles for Digital Community Currencies
}

\author{
Friedrich Chasin \\ University of Münster \\ friedrich.chasin@ercis.uni- \\ muenster.de
}

\author{
Florian Schmolke \\ University of Münster \\ florian.schmolke@ercis.uni- \\ muenster.de
}

\author{
Jörg Becker \\ University of Münster \\ becker@ercis.uni-muenster.de
}

\begin{abstract}
Community currencies are alternative currencies, which enable the mobilization of local resources for local needs and building resilient communities. They allow community members to perform economic transactions like buying products and paying for services using an alternative currency as a medium of exchange. For decades, regional, paper-based community currencies have been in use across the world. With the advent of the digital age, community currencies are increasingly moving into the digital space. Digital Community Currencies (DCCs) create opportunities for addressing challenges that traditional community currencies are facing, such as the inconvenience of handling two currencies in one wallet and the geographic limitation to a limited user population. This research builds upon characteristics and challenges of community currencies and derives six design principles from a literature review, an analysis of 16 community currency projects and an interview with a community currency project manager at the end of the project's life. The design principles serve as a basis for establishing resilient and scalable DCCs. They contribute to the limited IS research on phenomena of social sustainability and have major practical implications when implemented in existing community currency systems.
\end{abstract}

\section{Introduction}

Addressing the grand challenge of sustainability implies tackling issues across its three dimensions: Economic, ecological, and social [58]. While acknowledging the importance of each of these dimensions, the focus of the Information Systems (IS) discipline, most notably under the label of Green IS, has been on the ecological environment [5, 37, 59]. The opportunities for IS to become part of a solution for societal challenges such as poverty, hunger, and unemployment are not yet explored exhaustively.
In 1971, a favela in the Brazilian city of Curitiba was experiencing great difficulties with waste utilization, poverty and spreading diseases [43]. The city mayor realized that despite a difficult economic situation and great scarcity, the community still possessed underutilized resources in form of halfempty municipal buses and an oversupply of food that was growing well in the tropical climate. The mayor offered bus and food coupons to the community in exchange for bags of pre-sorted garbage [45]. Soon, a variety of goods could be bought with the coupons and over $70 \%$ of the local population were involved in the local alternative currency system [34]. There were initiatives to restore the city, clean the streets and create jobs, all without financial burdens to anyone such as raised taxes, loans, charities or redistribution of wealth.

The Curitiba example is a role model for the use of alternative currencies, which are simply put 'local money' that can only be used within a certain neighborhood or town [46]. They do not aim at replacing national currencies but target social problems of a community by mobilizing local resources for local needs [4] and empowering the end-users. Their possibilities and diffusion could be magnified repeatedly by introducing digital solutions as the majority of the world population are equipped with mobile devices [29]. Alternative currencies are hence currencies that exist alongside state currencies and can be divided into three groups often blurred and alternative exchange systems can overlap with or be part of each other: community currencies within a neighborhood, local currencies within a region and complementary currencies with an influence on the economy as complementary to national currencies [14].

One specific form of an alternative currency is a community currency, which is the focus of this work. A well-studied German community currency Chiemgauer [7, 53, 57] illustrates the basic functioning principle behind it. 3500 individuals, 500 businesses, and 300 associations participate in the Chiemgauerproject. To conduct transactions, customers can either use a special debit card ("Regiocard") or exchange 
Euro into Chiemgauer paper notes. For every transaction, a small percentage of the transaction value is donated to a social organization [19]. In addition to the donation, businesses pay a small fee for financing the non-profit institution that manages the currency. Moreover, a fee is required for paper bills older than six months as well as re-exchanging the currency into Euros.

Despite the success of the Chiemgauer project, community currencies are facing challenges, with many of them failing several years after their introduction [54]. Digitalization can empower the creation and survival of community currency projects by different means such as online networks. However, there is little to no guidance on how to capitalize on these new opportunities.

Against this background, IS research can offer solutions for the transition from paper-based to digital community currencies (DCCs) and address challenges of traditional community currencies such as the inconvenience of handling two currencies in one wallet and the geographic limitation to a limited user population while creating a strong embeddedness in local structures and enabling collaboration among users. However, neither the research nor the professional community has access to prescriptive knowledge on the characteristics of DCC projects. In this research, we ask the question: Which factors influence the success of digital community currencies. To demonstrate the design principles we furthermore aim at applying the design principles to existing community currencies.

In the spirit of design-oriented research in IS [23, 60], we aim at deriving design principles that can guide or constrain [28] the development of future DCCs. To do so, we conduct a literature review, analyze 16 community currency projects (Table 1), and study one project at its end-of-life in more detail. The insights are synthesized into actionable design principles [8]. The design principles in this work lay the ground for subsequent development of IT artifacts for sustainable communities that utilize DCCs. In addition to this synthetization, we have determined the degree of digitalization of the studied community currency projects. The individual projects are evaluated with a classification of 0-2. 0 represents no digital support, 2 stands fo no physical form of the community currency and 1 is a mix of physical and digital currency.
Table 1: List of community currency projects in empirical analysis

\begin{tabular}{|c|c|c|c|c|}
\hline Name & Country & Year & $\begin{array}{l}\text { Type of } \\
\text { currency }\end{array}$ & $\begin{array}{c}\text { Degree } \\
\text { of } \\
\text { digitali- } \\
\text { zation }\end{array}$ \\
\hline $\begin{array}{l}\text { Chiemgauer } \\
\text { Regiogeld }\end{array}$ & DE & 2002 & $\begin{array}{c}\text { Local } \\
\text { community } \\
\text { currency }\end{array}$ & 1 \\
\hline $\begin{array}{l}\text { Totnes } \\
\text { Pound }\end{array}$ & UK & 2007 & $\begin{array}{c}\text { Local } \\
\text { community } \\
\text { currency }\end{array}$ & 1 \\
\hline Elbtaler & $\mathrm{DE}$ & 2012 & $\begin{array}{c}\text { Local } \\
\text { community } \\
\text { currency }\end{array}$ & 1 \\
\hline $\begin{array}{l}\text { Bristol } \\
\text { Pound }\end{array}$ & UK & 2009 & $\begin{array}{c}\text { Local } \\
\text { community } \\
\text { currency }\end{array}$ & 1 \\
\hline Curitiba & $\mathrm{BR}$ & 1971 & $\begin{array}{c}\text { Local } \\
\text { community } \\
\text { currency }\end{array}$ & 0 \\
\hline Sardex & IT & 2010 & $\begin{array}{l}\text { Currency for } \\
\text { small and } \\
\text { medium sized } \\
\text { enterprises }\end{array}$ & 2 \\
\hline $\begin{array}{l}\text { Samen } \\
\text { Doen }\end{array}$ & NL & 2014 & $\begin{array}{l}\text { Local } \\
\text { community } \\
\text { currency }\end{array}$ & 2 \\
\hline Carlo & DE & 2005 & $\begin{array}{c}\text { Local } \\
\text { community } \\
\text { currency }\end{array}$ & 0 \\
\hline WIR & $\mathrm{CH}$ & 1934 & $\begin{array}{c}\text { Bank for } \\
\text { small and } \\
\text { medium sized } \\
\text { enterprises }\end{array}$ & 2 \\
\hline $\begin{array}{l}\text { Dane } \\
\text { County } \\
\text { Timebank }\end{array}$ & US & 2006 & $\begin{array}{c}\text { Mutual } \\
\text { Credit } \\
\text { System }\end{array}$ & 2 \\
\hline EuroCat & ES & 2013 & $\begin{array}{c}\text { Currency } \\
\text { measured } \\
\text { in trust / } \\
\text { endorse- } \\
\text { ments }\end{array}$ & 2 \\
\hline $\begin{array}{l}\text { Fureai } \\
\text { Kippu }\end{array}$ & JP & 1995 & $\begin{array}{l}\text { Healthcare } \\
\text { Currency }\end{array}$ & 2 \\
\hline TradeQoin & NL & $\begin{array}{c}2013 \\
- \\
2019\end{array}$ & $\begin{array}{l}\text { Currency for } \\
\text { business en- } \\
\text { trepreneurs }\end{array}$ & 2 \\
\hline Sonantes & FR & 2014 & $\begin{array}{c}\text { Local } \\
\text { community } \\
\text { currency }\end{array}$ & 2 \\
\hline $\begin{array}{l}\text { Exeter } \\
\text { Pound }\end{array}$ & UK & $\begin{array}{c}2014 \\
- \\
2018\end{array}$ & $\begin{array}{c}\text { Local } \\
\text { community } \\
\text { currency }\end{array}$ & 1 \\
\hline
\end{tabular}




\section{Digital Community Currencies and their Challenges}

\subsection{Dimensions of Digital Community Currencies}

In general, community currencies are alternative currencies to the government cash and similar to local currencies and complementary currencies [14]. By definition, the three mainly differ by their focus on a specific community for community currencies, a specific territory for local currencies, or their influence on the economy as complementary to national currencies for complementary currencies (ibid). In practice, the lines between alternative currencies and related phenomena are often blurred and alternative exchange systems can overlap with or be part of community currency.

In order to get a clearer idea of the dimensions of DCCs, the following section presents various projects from Table 1 and classifies them according to their different functionalities. Therefore, different forms of currency systems can be distinguished by examining their technological base [13].

First, simple technological architectures include scriptural balances, online marketplaces, debit cards, and point-of-sale. They all require an issuing institution and thus a highly centralized organization. The Comox Valley Local Exchange Trading System (LETS) from Canada, established in 1985, was based on simple scriptural balances in its beginnings [11, 48]. It is a mutual credit system (MCS) - a zero-balance system, where "one person's credit equals another's debit to the system, accounts always sum to zero and both the value and utility of the currency is maintained by trust in other members to meet their commitments" [54]. Time banks like the Dane County Timebank for exchanging hours of service between community members can be based on simple technological architecture as well.

In contrast to that, there are complex technical architectures such as SMS, mobile applications, internet banking, Near-Field-Communication (NFC) and cryptocurrencies. They are complex as they all enable a more decentral organization. Based on the blockchain technology, social cryptocurrencies have evolved. They are digital currencies offering solidarity finance, which are distinct from DCCs mainly because of excessively high growth and expansion rates without geographic boundaries [14]. However, with community currencies entering the digital world and cryptocurrencies pursuing social goals, the line between the two can be vague [50].
Second, the above-mentioned difference between central or decentral organization structures is manifested in the governance structure, which can be shared or proprietary [13]. Shared governance can be operated in the form of a community bank or association such as Elbtaler. Proprietary governance, on the other hand, can be found at TradeQoin, a private company organizing a currency only for small and medium-sized enterprises. Community currencies that focus mostly on social and economic, sometimes environmental goals, often base on voluntary and activist-led structures and therefore have shared governance [54].

Furthermore, governance structures vary across DCCs depending on the design of currency transactions between two parties. One-sided platforms only allow transactions between members of the same user group, such as the WIR-bank in Switzerland between businesses. Two-sided platforms allow transactions between different parties, e.g. businesses and customers. Multi-sided systems reach from transactions between individuals and the government, integration of transport and telecommunication services to care projects [13]. The introductory example of Curitiba would be such a case.

Third, loyalty programs are not to be confused with alternative currencies. They serve an economic purpose, mainly establishing a commitment of a customer for a brand/sponsor and thus lead to an economic advantage [3]. Nevertheless, the general reward and payment system is close to a currency system and could possibly serve as an alternative currency if specifically targeting a sustainability purpose [10].

Finally, a characteristic that applies both to alternative currencies and most national ones is virtuality [21, 33]. Virtual does not necessarily mean digital, but that it is not backed by any real-life commodity such as gold [6, 24, 32]. Examples like the Fureai Kippu can be found in Table 1. Virtual currencies represent the so-called 'fiat'-money. Fiat describes "the practice of giving money value by the mere executive decree of the state. Almost all world currencies today are ey: they have value because governments say so" [6].

Having distinguished and discussed the nature of community currencies and their 'relatives', community currencies enforce regional economic flows and cooperation, increase the belonging to a community, reduce emissions of transport and high-risk financial speculation [18]. Four factors have been identified as major contributions of community currencies for the society and end-user empowerment: Reducing inequality and social exclusion, supporting small and medium-sized enterprises, positive environmental 
impact and the democratization of services and organizations [10]. The Chiemgauer organization states, that the currency builds stability for the community: Even during and after the financial crisis in 2008, it had stable turnovers about twice as high as the Euro. This and hundreds of other examples of community currency projects suggest, that a successful community currency creates resilience [2, 22, 41, 49]. Resilience is "the ability of a system to sustain itself through change via adaptation and occasional transformation" [36]. If communities meet a large share of their demand from local production and facilitate exchange between members with an alternative currency, their dependence from the global economy declines and resilience grows [42].

\subsection{Challenges}

A literature review and the study of community currency projects (Table 1) on academic literature community currency projects reveal a plethora of challenges for community currencies. These challenges were identified in an iterative process of reviewing individual sources including the literature and the presented DCC platforms within the team of participating researchers. An interview with the manager of a deceased DCC platform provided an exclusive view on specific challenges that have been included in the following.

After an initial phase receiving regional development funds and donations, unstable funding streams are often a challenge for the platforms [46, 53]. Many community currencies serve the purpose of strengthening the bond between members of the community. In contrast, a digital platform holds the risks of losing the community feeling and exclude digitally illiterate users [13]. Another challenge is networking between geographically scattered community currencies speaking different languages. The language barrier has so far been a hurdle for communication and information exchange in many cases [54]. Also legal issues increase complexity when introducing a DCC, as stated by a community currency project manager: "To issue a digital version, for regulatory compliance we would need to go through a credit union, which we don't have in [town name], or to apply to the Financial Services Authority for regulatory approval, a very big process." The full interview transcript is not attached, as the text body would exceed the page limitation.

In summary, the following four challenges can be identified from the interview and the literature on community currency and related phenomena as presented in 2.1:
- Unstable funding streams.

- Loosing members in digital transformation.

- Absence of a network for the exchange of information.

- $\quad$ Legal issues of the digitalization.

However, there are substantial differences between existing types of community currencies. Within the analyzed cases, there are monetary, time-based and trust-based currencies. The diverse nature of the systems, as well as their geographic particularities, represent additional barriers for knowledge exchange and adoption of lessons learned from other systems [53].

All these challenges place a burden on community currency projects. Failed projects show that after a period of growing interest among community members and funding entities, the inability of reaching a critical mass leads to platforms ceasing operations in the long run [54]. Six principles are introduced in the following, which can guide the design of digital community currencies. We build each principle upon the extant research with the aim of addressing the discussed challenges of the community currencies.

\section{Design Principles for Digital Community Currencies}

\subsection{Methodology}

In the following section, the six design principles for digital community currencies are presented, which are taken from a literature review as well as an interview with a community currency project manager at the end of the project's life. The literature review was based on keyword combinations such as "community / alternative / local / digital currency", "time bank", "trading schemes", "grassroot innovations" were searched in the IS top basket, conference proceedings (e.g. ACIS, AMCIS, HICSS, ECIS, ICIS) and other IS outlets. Furthermore, a backward and forward search in relevant literature were used. As stated in the introduction, DCC apart from cryptocurrency is not a mature research field in the IS domain. Thus, most information was retrieved from knowledge platforms such as the International Journal of Community Currency Research (IJCCR). It must be noted that not every challenge has been observed in each DCC platform and academic literature reported on the challenges to a different extent. Within a team of three researchers, the literature, as well as the knowledge platforms concerning the DCC, were each independently analyzed in order to conclude on common, coherent principles in a joint discussion. The research represents 
the synthesis of most reoccurring challenges into principles that can help to address these challenges.

These derived six design principles are illustrated in Figure 1 and described in detail in the following paragraphs. For some challenges as well as principles there is however no proved solution and this manuscript goes beyond the current status quo mentioned in the introduction and proposes possible innovative solutions.

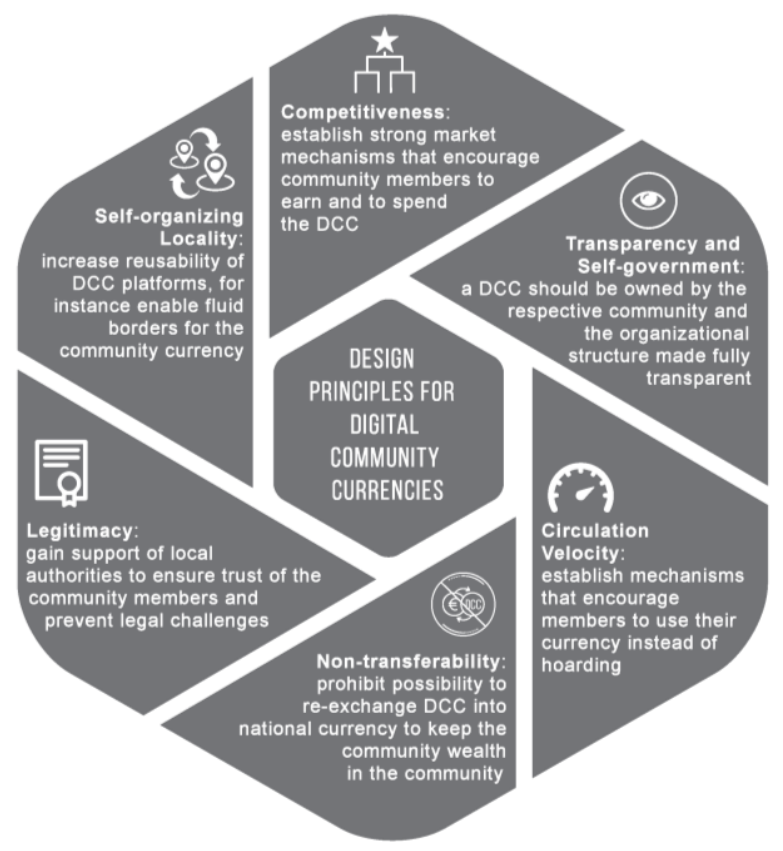

Figure 1: Overview of design principles for digital community currencies

\subsection{Competitiveness}

If goods are allocated in planned economies based on socialist principles, history has shown that they are designed to fail [38]. In contrast, competitive markets have many buyers and sellers and prices are determined by market mechanisms like supply and demand, not by any superior entity [40]. They are voluntary exchanges of money, goods, and services and include benefits such as innovation, efficiency, and freedom of individual choice [51]. This logic entails, that no individual or business is interested in conducting activities with low monetary rewards [55]. Community currencies usually operate in the nonprofit and voluntary sector, which is characterized by unprofitable social activities such as healthcare and education [1]. In contrast to the market economy, demand for social activities is high and supply is low.
Applying the principle of competitiveness turns the tables as DCCs should establish strong market mechanisms at the basis of the non-profit and voluntary sector and set incentives for actors of the market economy to compete for supply of social needs. This supply can be complemented by multi-sided transactions, which also allow for constant funding streams.

\subsection{Transparency and Self-government}

Each organization depends on some form of governance in the form of control [26]. Control is often delegated to agents, which implies the danger of disagreements between principal and agent [30]. The danger lies within an asymmetry of information, which can lead to high overhead costs and disparity or loss of power (ibid). Community currencies with all types of governance structures deal with control and delegation as well as complex stakeholder interests [44]. A possible way to circumvent the delegation of control is full information and transparency so that stakeholders can claim their interests and thereby exercise regulative power [27]. Social commons, similar to public or common goods, rely on collective action and selfmanagement [39].

A DCC should be a social common to root the DCC within the community, prevent misuse and enable transparency and self-government.

\subsection{Circulation Velocity}

Money has multiple functions such as storing value, being compact, dense, rare, easy to count and portable $[6,56]$. These functions are fundamental for enabling exchanges in the market economy. However, they bring the challenge of precautionary 'hoarding', which can reduce the liquidity of an economy (change of ownership in transactions)[25]. The challenge of hoarding is magnified in the context of a DCC if the community recognizes it as stable and resilient, which is an important factor in the first place. One negative example could be community members collecting savings in the form of the DCC for their future pension. An indicator for measuring whether consumers and businesses are saving or spending is the velocity of money, which is defined as the frequency of transactions (the number of times one dollar is spent to buy goods and services per unit of time) [16]. One possible instrument to increase the frequency of transactions is to degrade currency value over time [20]. This mechanism can be an effective, yet for most traditional consumers and economists too radical way for increasing the circulation velocity. 
In practice, a DCC should include mechanisms, which encourage users to spend instead of hoarding. The digital design of a community currency can provide diverse opportunities for such mechanisms.

\subsection{Non-transferability}

In the global economy, currencies serve the purpose of transferring value between geographical and geopolitical borders [47]. Economic unions and institutions, as well as exchange rates, facilitate trade for international companies [17]. Operating in a global economy, a company can profit from the strong purchasing power of customers while paying low wages in countries with low social standards [15]. It is the opposite of the idea of a local economy, which accumulates local resources. This way, international businesses can withdraw value from communities to pay obligations in the form of debt and interest, which have no connection to the community [4].

A DCC should exclude the possibility of reexchange it into any other currency to prevent community members and businesses from extracting value from the community.

\subsection{Legitimacy}

Governments can function as a barrier or as empowerment towards innovation as they control tax, financial, regulatory and monetary policy [31]. Especially innovative ideas that challenge existing structures often have to cope with restrictive regulation [9]. Community currencies can lead to such disruptive innovations [35] and are therefore at risk to be held back. For a DCC to be successful, it requires confidence by the local population. An effective way of creating trust in a monetary system is official backing by the government [32]. This can be achieved with the inclusion of the DCC in the tax system and other official obligations, such as rents and wages. Support of the local authority eases legal and administrative hurdles and offers long-term funding options to the managing organization.

DCCs should incorporate legitimacy by a design that can gain official support of the local authority in order to ensure the trust of the population in the DCC and facilitate legal issues.

\subsection{Self-organizing Locality}

Community currencies develop independently with different geographic focus and do commonly not exchange information between projects [54]. That leads to hundreds of community currency initiatives fighting their challenges on their own [12]. The transition of an analog to a digital world confronts community currencies with similar obstacles, such as the inclusion of digitally illiterate citizens [10]. DCC prototypes and other knowledge could be shared in an active online network with automated translation. Still, every DCC would have to organize itself and maintain its platform individually. DCC initiatives can extend the scope of a community currency across the borders of a local community. Meeting the suggested principles, enhancing the local economy and global sustainability at the same time is no longer a contradiction. Lietaer et al. [33] shape the idea of an ecosystem of purposeful currencies, which complement national currencies. Those currencies aim at social, environmental or economic sustainability. There can be different options for a currency that has a maximum value $\mathrm{x}$ and degrades with the increasing factor $y$. One possible factor is distance: To set the highest purchasing power of the currency, where turnover is the highest and decrease with geographical distance. Locations competing for the highest turnover would have a positive impact as they target sustainability purposes. The digital design of a DCC allows for this kind of creative and complex solutions and has no limits in terms of a village, city, country or continent.

Accordingly, a DCC should not limit itself to a local community but enable fluid borders through selforganizing locality so that participation is open to every interested individual and economic entity to enhance sustainability. This last principle is only enabled by digital solutions and creates a completely new context for the scope and impact of digital community currencies.

As we are aware these design principles can be seen as an initial set of principles drawn from secondary literature. However, they are yet to be validated, and their usefulness as a basis from which to evaluate existing currencies is not demonstrated. Because the design principles have not been validated, it is impossible to know they are sufficiently comprehensive in theory, or useful in practice. To do so, we need to gather further primary data at this point from yet to implement DCC platform of our own.

\section{Validation of Design Principles}

We applied the principles to the set of community currency platforms listed in Table 1 in order to provide an overview of principles that can be found within platforms that currently operate in practice. To validate 
three researchers analyzed the projects independently and discussed the presence of the proposed design principles in several iterations.

The results shown in Table 2 represent the consensus on the degree of design principle implementation in each platform case. Therefore, we introduced the following three possible states for a community currency project:

+ for supporting the design principles,

- for not supporting the design principles and

$\sim$ for partial supporting the design principles.

Table 2: Overview of applied principles on existing community currencies

\begin{tabular}{|c|c|c|c|c|c|c|}
\hline Platform & 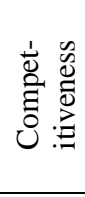 & 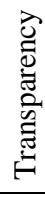 & $\frac{\tilde{\sigma}}{\frac{\tilde{\sigma}}{\tilde{J}}}$ & 乙. & 忍 & 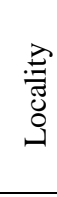 \\
\hline & Co & $\mathbf{T}$ & $\mathbf{C i}$ & $\mathbf{N}$ & Le & Lo \\
\hline $\begin{array}{l}\text { Chiemgauer } \\
\text { Regiogeld }\end{array}$ & + & + & + & - & + & + \\
\hline $\begin{array}{l}\text { Totnes } \\
\text { Pound }\end{array}$ & + & + & - & - & $\sim$ & $\sim$ \\
\hline Elbtaler & + & + & $\sim$ & + & $\sim$ & $\sim$ \\
\hline $\begin{array}{l}\text { Bristol } \\
\text { Pound }\end{array}$ & + & $\sim$ & $\sim$ & $\sim$ & + & $\sim$ \\
\hline Curitiba & + & - & - & + & + & + \\
\hline Sardex & + & $\sim$ & $\sim$ & + & + & - \\
\hline SamenDoen & + & - & - & + & - & - \\
\hline Carlo & + & + & + & - & $\sim$ & - \\
\hline WIR & - & - & - & - & - & - \\
\hline $\begin{array}{l}\text { Dane } \\
\text { County } \\
\text { Timebank }\end{array}$ & - & $\sim$ & - & + & $\sim$ & - \\
\hline $\begin{array}{l}\text { Fureai } \\
\text { Kippu }\end{array}$ & - & - & - & + & + & - \\
\hline Sonantes & + & - & - & + & $\sim$ & $\sim$ \\
\hline $\begin{array}{l}\text { Exeter } \\
\text { Pound }\end{array}$ & - & - & - & + & - & + \\
\hline
\end{tabular}

A closer look at the presence of these design principles and the specifics with which they have been implemented lead us to the following three major observations.

\subsection{Observation 1: Lack of Transparency}

In line with the academic insights, community platforms are challenged by establishing appropriate organizational structures [43]. In most cases, community currency platforms fail at disclosing the organizational structures behind the project $(\mathrm{T})$. For instance, platforms like SamenDoen, WIR, and EuroCat focus on explaining and advertising the general idea of a community currency and leave the explanation of how the organizational structure is implemented and which roles and individuals are behind the project. This signifies the lack of the proposed transparency ( $\mathrm{T}$ ) and can lead to a lack of trust among the potential participants. Such lack of trust is a major impediment for the diffusion of the currency within a community. [44]

A lack of trust can be furthermore driven by nontransparent business models behind the projects. For instance, in the project SamenDoen, a point system was observed. In this points system, each participant receives points in accordance with his purchase value in a participating store. The number of points for each transaction depends only on the money spent in the local store. These points can then be exchanged either for further purchases, rewards or services [3]. Such a point system for the purchase of local goods that is structured as a community currency can lead to economic interests arising within the organizational structures by using customer data as a means of financing the governing organization. This creates a situation where project participants can quickly lose trust in the platform and its governing organization.

Surprisingly only a few of the analyzed projects provide transparency regarding the organizational structures of the governing entity. For instance, the Chiemgauer Regiogeld system explicitly implements transparency (T) and facilitates transparent communication with the participants. The annual general meeting and periodic meetings are announced in advance, and all members are invited on a voluntary basis [7, 57]. This facilitates confidence in the community currency system in the Chiemgauer region.

\subsection{Observation 2: Hidden Aim of Protecting Capital from Inflation}

In platforms like Totnes Pound, Bristol Pound, and $W I R$, it is possible to obtain community currencies by exchanging the national currency into community 
currency without a fee. Furthermore, if the community currency does not have a time-value limit at all or the time-value limit is longer than a year. This lacks the incentive to quickly put the community currency back into circulation except that it does not receive an interest rate and will store the value $[6,56]$. Only the personal attitude and belonging to the community serves as an incentive to use the community currency. This does not support circulation (Ci) as the community currency rest unused for the community. Eventually, this stored community currency can be converted back into the national currency which is not recommended in die design principles of digital community currencies.

This combination of missing implementations of an incentive for the community currency circulation as well as the lack of non-transferability $(\mathrm{N})$ can lead to a possibility of using the community currency as an investment with indirect interest rates due to inflation [25]. Purchasing a community currency against the national currency at a given time creates a fixed value of the money invested. If this community money is exchanged into national currency after a certain period of time, the real purchasing power can be increased. This effect can motivate participants to engage with the currency yet prevents the community currency to strengthen the community and would likely cause a skeptical assessment of the currency by legislators (Le).

\subsection{Observation 3: Risk of Movement from Complementary towards Substitute Currency}

On platforms with digital community currencies, there are currently no restrictions on the usability of the currency from other regions. For example, currencies such as the Totnes Pound and Sonantes can be bought analogously and digitally by the national currency. These community currencies can then be used by companies as a means of payment. For instance, the Totnes Pound project emphasizes that the system is designed for the city of Totnes, but also a wider distribution is set as a goal for this community currency. This is not in line with the locality (Lo). This approach and the supra-regional (supra-urban) use of digital community currencies could lead to creating a substitute for a national currency, which is not the aim of community currencies [14].

One of the main goals of community currencies is to strengthen a region, a city or a neighborhood. In doing so, it is important to clearly define the term 'region' and adhere to this definition [13, 46]. Thus, the community currency of the Sonantes platform can be used in the entire Pays-de-la-Loire region (as far as companies participate) and is thus available in the entire federal state of France. This can already be seen as supra-regional, as the potential community behind it is too heterogeneous with different challenges. The lack of a community aspect is a step towards having an alternative currency - something that could likely cause skeptical assessment of the currency by legislators (Le) and is not the initial goal of community currency. Going back to the suggested principles of self-organizing locality (subsection 3.7), such supraregional developments of community currencies are problematic as they lose the principle of locality (Lo) by assigning same value for a currency unit in the entire regions. Contrarily, self-organizing locality facilitates local transactions by assigning higher value to a purposeful currency unit for transactions [33] that are initiated close to where the unit was generated.

\section{Discussion and Next Steps}

The six design principles of Figure 1 presented in this work can have major implications for existing and future DCCs on the identified challenges. They enforce knowledge sharing between community currency projects and expand existing regional boundaries. Both on a small and large scale, the proposed principles can bring resilience and sustainability transformation to societies. The diffusion of digital technologies and focus on local economies can reduce dependence on high-risk mechanisms of the global financial economy as well as strengthen the collaboration among individuals of a community by providing a reward system for the participants. DCCs being a social phenomenon that can empower the end-user of IS, the design principles extend also the research area of Green IS, which mostly focused on environmental aspects of sustainability to date. Nevertheless, it is to investigate why certain community currencies failed to keep running as well as determine the problems some of the community currency platforms ran into that leads to the decision to shut down the online support of the currency. Furthermore, future work will have to examine whether the design principles are equally applicable to every community currency project, or whether they need to be differentiated on a case-bycase basis.

The research is currently bound to a limited number of DCCs selected among academic literature as the overwhelming majority of community currencies still operates at least partly with paper bills. Furthermore, information about empirical cases does almost exclusively base on secondary information available. In future work, we are going to collect empirical data from the implementation of a DCC to verify the design 
principles as well as validating the challenges of community currencies from chapter 4 .

The major limitation of this work is the lack of extensive evaluation of the design principles. The source for the principles is primarily academic literature that supports chosen design principles from the theoretical point of view. Although we were able to find support for the design principles in the interview material, an extensive evaluation of the design principles is required. On the one hand, a greater number of interviews and workshops with experts need to be performed where the design principles can be presented and extensively discussed. Second, prototypes of DCC platforms that follow the presented design principles need to be developed and evaluated against the existing platforms. These steps combined with the implementation of the principles in a realworld community can be subsumed under the method of Action Design Research [52]. With the proposed design principles, we hope to spur discourse on the phenomenon of digital community currencies within the IS community and to contribute to the architecture and the design of resilient communities of tomorrow. Moreover, a concluding statement on how valid the design principles are having to be made in future work with this complete implementation of the principles and a detailed examination of the implemented design principles.

\section{References}

[1] Achleitner, A.-K., P. Heister, and E. Stahl, "Social Entrepreneurship - Ein Überblick", Finanzierung von Sozialunternehmern, 2007.

[2] Aldrich, D.P., and M.A. Meyer, "Social Capital and Community Resilience", American Behavioral Scientist, 2015.

[3] Berman, B., "Developing an Effective Customer Loyalty Program", California Management Review 49(1), 2006, pp. 123-148.

[4] Berniker, E., Only a Ten Hour Week - Architecture for a Sustainable Society of Plenty, 2017.

[5] Vom Brocke, J., S. Seidel, P. Loos, and R.T. Watson, "Green IS: Information systems for environmental sustainability", Business and Information Systems Engineering, 2013.

[6] Castronova, E., Wildcat currency: How the virtual money revolution is transforming the economy, 2014.

[7] Cato, M.S., and M. Suárez, "Stroud Pound: A Local Currency to Map, Measure and Strengthen the Local Economy", International Journal of Community Currency Research 16, 2012, pp. 106-115.

[8] Chandra, L., S. Seidel, and S. Gregor, "Prescriptive knowledge in IS research: Conceptualizing design principles in terms of materiality, action, and boundary conditions", Proceedings of the Annual Hawaii International Conference on System Sciences, (2015).

[9] Chasin, F., M. Matzner, M. Löchte, V. Wiget, and J. Becker, "The Law: The Boon and Bane of IT-Enabled Peerto-Peer Sharing and Collaborative Consumption Services", Proceedings of the 12th International Conference on Wirtschaftsinformatik (WI 2015), (2015), 332-347.

[10] Community Currencies in Action (CCIA), People Powered Money - Designing, developing and delivering community currencies, New Economics Foundation, London, 2015.

[11] Croall, J., LETS act locally: the growth of Local Exchange Trading Systems, Calouste Gulbenkian Foundation, 1997.

[12] DeMeulenaere, S., "2007 Annual Report of the Worldwide Database of Complementary Currency Systems", International Journal of Community Currency Research, 2007.

[13] Diniz, E., E.S. Siqueira, and E. van Heck, "Taxonomy for Understanding Digital Community Currencies: Digital Payment Platforms and Virtual Community Feelings", Globdev 2016, 2016.

[14] Diniz, E.H., R. Itapeva, S.P. Brazil, F. Daneluzzi, A.K. Cernev, and D. Rodrigues, "Social Cryptocurrencies : blockchain adoption in solidarity finance", Thirty ninth International Conference on Information Systems, San Francisco(Blanc 2011), 2018, pp. 1-9.

[15] Dr. Fuders, F., "Die natürliche Wirtschaftsordnung als Option nach dem Zusammenbruch”, (October 2009), 2009.

[16] Federal Reserve Bank of St. Louis, "Velocity of M2 Money Stock”, 2018.

[17] Feenstra, R.C., Advanced international trade: theory and evidence, Princeton university press, 2015.

[18] Gelleri, C., "Theorie und Praxis des Regiogeldes", Working Paper als Beitrag zur oikos-Konferenz Uni St. Gallen 2006 "Die Zukunft des Geldes”, 2006.

[19] Gelleri, C., "Der Chiemgauer in der Praxis", 2018.

[20] Gesell, S., The natural economic order, Owen London, 1958.

[21] Ghizoni, S.K., "Nixon Ends Convertibility of US Dollars to Gold and Announces Wage/Price Controls", Federal Reserve History, 2013.

[22] Graugaard, J.D., "A tool for building community resilience? A case study of the Lewes Pound", Local Environment, 2012.

[23] Gregor, S., and D. Jones, The Anatomy of a Design Theory, 2007.

[24] Groppa, O., "Complementary Currency and its Impact on the Economy", International Journal of Community Currency Research 17, 2008, pp. 45-57.

[25] Guerrieri, V., and G. Lorenzoni, "Credit crises, precautionary savings, and the liquidity trap", The Quarterly Journal of Economics 132(3), 2017, pp. 1427-1467.

[26] Hart, O., "Corporate Governance: Some Theory and Implications", The Economic Journal, 1995.

[27] Hess, D., "Social reporting and new governance regulation: The prospects of achieving corporate accountability through transparency", Business Ethics Quarterly 17(3), 2007, pp. 453-476. 
[28] Hevner, A., and S. Chatterjee, Design Research in Information Systems, Springer US, Boston, MA, USA, 2010. [29] ITU, "ICT facts and figures 2017", 2017.

[30] Laffont, J.-J., and D. Martimort, The theory of incentives: the principal-agent model, Princeton university press, 2009.

[31] Leigh, N.G., and E.J. Blakely, Planning local economic development: Theory and practice, SAGE publications, 2016.

[32] Lerner, A.P., "Money as a Creature of the State", The American Economic Review 37(2), 1947, pp. 312-317.

[33] Lietaer, B., C. Arnsperger, S. Goerner, and S.

Brunnhuber, "Money and sustainability: the missing link--A report from the Club of Rome--EU Chapter to the Finance Watch and the World Business Acadamy”, 2012.

[34] Lietaer, B., and S. Belgin, "The story of Curitiba in Brazil", 2010.

[35] van der Linden, M.J., and C. van Beers, "Are Private (Digital) Moneys (Disruptive) Social Innovations? An Exploration of Different Designs", Journal of Social Entrepreneurship, 2017.

[36] Magis, K., "Community resilience: An indicator of social sustainability”, Society and Natural Resources, 2010.

[37] Malhotra, A., N. Melville, and R. Watson, "Information Systems and Environmental Sustainability", MIS Quarterly 24, 2010.

[38] McKinnon, R.I., The order of economic liberalization: Financial control in the transition to a market economy, JHU Press, 1993.

[39] Meyer, C., and M. Hudon, "Money and the Commons: An Investigation of Complementary Currencies and Their Ethical Implications", Journal of Business Ethics, 2018, pp. $1-16$.

[40] Nicholson, W., and C. Snyder, Microeconomic theory: Basic principles and extensions, Nelson Education, 2011.

[41] Norris, F.H., S.P. Stevens, B. Pfefferbaum, K.F. Wyche, and R.L. Pfefferbaum, "Community resilience as a metaphor, theory, set of capacities, and strategy for disaster readiness", American Journal of Community Psychology, 2008.

[42] North, P., "Money and liberation", The micropolitics of alternative currency movements [ "Dinero y liberación. Las micropolíticas de los movimientos de moneda alternativa»], 2007.

[43] Primavera, H., "Social Currencies and Solidarity of economy: an enduring bond of common good", Working USA: The Journal of labor and society, 2010.

[44] van Puyvelde, S., R. Caers, C. du Bois, and M. Jegers, "The Governance of Nonprofit Organizations: Integrating Agency Theory With Stakeholder and Stewardship Theories", Nonprofit and Voluntary Sector Quarterly, 2012. [45] Rehan, G., and H. Mahmoud, "The Integration between Transportation Solutions, Economic Development and Community Development as an Approach for Sustainability-
A Case Study of", World Academy of Science, Engineering and ..., 2011.

[46] Richey, S., "Manufacturing Trust: Community Currencies and the Creation of Social Capital", Political Behavior 29(1), 2007, pp. 69-88.

[47] Rose, A.K., and E. Van Wincoop, "National money as a barrier to international trade: The real case for currency union”, American Economic Review, 2001.

[48] Schraven, J., "Mutual credit systems and the commons problem: why community currency systems such as LETS need not collapse under opportunistic behaviour",

International Journal of Community Currency Research 5(4), 2001, pp. 1-10.

[49] Scott-Cato, M., and J. Hillier, "How could we study climate-related social innovation? Applying Deleuzean philosophy to Transition Towns", Environmental Politics, 2010.

[50] Scott, B., CASH IN THE ERA OF THE DIGITAL PAYMENTS CASH IN THE ERA OF THE DIGITAL, Amsterdam, 2018.

[51] Scully, G.W., "The Institutional Framework and Economic Development", Journal of Political Economy 96(3), 1988, pp. 652-662.

[52] Sein, Henfridsson, Purao, Rossi, and Lindgren, "Action Design Research”, MIS Quarterly 35(1), 2011, pp. 37.

[53] Seyfang, G., and N. Longhurst, "Desperately Seeking Niches: Grassroots Innovations and Niche Development in the Community Currency Field", Global Environmental Change, 2013.

[54] Seyfang, G., and N. Longhurst, "Growing Green Money? Mapping Community Currencies for Sustainable Development", Ecological Economics 86, 2013, pp. 65-77.

[55] Simon, H.A., "Organizations and markets", Journal of economic perspectives 5(2), 1991, pp. 25-44.

[56] Spahn, H.-P., From gold to euro: On monetary theory and the history of currency systems, Springer Science \& Business Media, 2001.

[57] Thiel C, Complementary Currencies in Germany: The Regiogeld System, Augsberg, 2011.

[58] Watson, Boudreau, and Chen, "Information Systems and Environmentally Sustainable Development: Energy Informatics and New Directions for the IS Community", MIS Quarterly, 2010.

[59] Watson, Boudreau, and Chen, "Information Systems and Environmentally Sustainable Development: Energy Informatics and New Directions for the IS Community", MIS Quarterly, 2017.

[60] Winter, R., "Design science research in Europe", European Journal of Information Systems 17, 2008, 470475. 